\title{
DESEMPENHO INDUSTRIAL DE PÓ FLUXANTE COM TEOR REDUZIDO DE FLÚOR PARA AÇOS COM BAIXO TEOR DE CARBONO*
}

\author{
Rodrigo Seara Martins ${ }^{1}$ \\ Leonardo José Silva de Oliveira² \\ Everton Paço Cunha ${ }^{3}$ \\ Alexandra de Almeida Diego ${ }^{4}$
}

\section{Resumo}

Foram realizados testes industriais com cerca de uma tonelada de pó fluxante com teor de flúor da ordem de 1,0\%, denominado ultrabaixo teor de flúor (UBF). Os testes foram realizados em 29 corridas de aços com baixo teor de carbono acalmados ao alumínio (AA BC) na Aciaria 2 da Usiminas em Ipatinga. Ao longo do processamento industrial, os dados operacionais foram analisados, coletadas amostras para avaliação das propriedades físico-químicas da escória líquida e as válvulas submersas foram separadas para medir a taxa de desgaste. Tanto as caracterizações realizadas quanto o desempenho industrial evidenciaram que as propriedades relativas à taxa de fusão, lubrificação e cristalização estão de acordo com as necessidades operacionais para a produção de aços AA BC. Por fim, os resultados de desgaste da válvula submersa mostram um ganho significativo com o uso do pó fluxante UBF. A taxa média de desgaste foi aproximadamente $40 \%$ inferior à obtida com o uso do pó fluxante comercial (teor de flúor na ordem de 7,5\%).

Palavras-chave: Pó fluxante; Baixo teor de flúor; Desgaste de válvula submersa.

\section{INDUSTRIAL PERFORMANCE OF MOULD POWDER WITH REDUCED FLUORINE CONTENT FOR LOW CARBON STEELS}

\begin{abstract}
Industrial tests were carried out with about a ton of mould powder with $1.0 \%$ of fluorine content, called ultralow fluorine content (ULF). The tests were conducted in 29 heats low carbon aluminum killed steel (LCAK) at Usiminas Steelshop \#2 in Ipatinga. Throughout the industrial processing, operational data and samples were collected for evaluation of physicochemical properties of the slag and submerged entry nozzles were separated to measure wear rate. The characterizations and the industrial performance indicated that the properties related to the melting rate, lubrication and crystallization are according to the operational needs to production of LCAK steel. Finally, the submerged entry nozzle wear was significant lower with the use of flux powder ULF. The average wear rate was about $40 \%$ lower than that obtained using the commercial mould powder (with $7.5 \%$ fluorine content).

Keywords: Mould powder; Low fluorine content; Submerged entry nozzle wear.

1 Engenheiro Mecânico, Pós-Graduação em Metalurgia, Engenheiro de Produção Pleno, Gerência Técnica de Aciaria, Usinas Siderúrgica de Minas Gerais - Usiminas, Ipatinga, MG, Brasil.

2 Engenheiro Metalurgista, Mestre em Metalurgia Extrativa, Pesquisador Especialista, Pesquisa e Desenvolvimento, Usinas Siderúrgicas de Minas Gerais - Usiminas, Ipatinga, MG, Brasil.

3 Engenheiro de Materiais, Gerente de Lingotamento Contínuo, Gerência de Lingotamento Continuo, Usinas Siderúrgica de Minas Gerais - Usiminas, Ipatinga, MG, Brasil.

4 Engenheira de Materiais, Mestre em Ciências e Engenheira de Materiais, Engenheira de Desenvolvimento de Produto, Carboox Resende Química Ind. Com. Ltda., Resende, RJ, Brasil.
\end{abstract}




\section{INTRODUÇÃO}

A prática de lingotamento contínuo requer um grande controle operacional para se garantir a qualidade superficial das placas produzidas. Aliado ao desenvolvimento das técnicas de lingotamento ocorreu um aumento da necessidade de inovações nos insumos usados no processo. Com isso, o uso de pós fluxantes de alto conteúdo tecnológico tem se tornado imprescindível, influenciando na produção de placas isentas de defeitos superficiais.

Em linhas gerais, o comportamento do pó fluxante no veio baseia-se nas seguintes premissas: fusão adequada, infiltração, absorção de inclusões, isolamento térmico, reoxidação do aço e lubrificação consistentes com o processo e solidificação/cristalização ajustadas as características do aço.

Quando se fala em novas tendências para pós fluxantes, a busca principal é a substituição dos minerais ricos em flúor da constituição do insumo (fluoreto de sódio, criolita ou fluorita). Estes minerais podem reagir formando compostos gasosos que, na região de resfriamento secundário, geram ácidos que são prejudiciais à saúde e ao meio ambiente, além de causarem o desgaste prematuro dos equipamentos de lingotamento contínuo [1].

Além dos benefícios ambientais relacionados à redução do flúor é possível se obter outros ganhos em relação à segurança e custos operacionais. O principal deles e, talvez, o mais claro de se quantificar é o desgaste da válvula submersa. A Figura 1 apresenta o efeito da presença de fluoretos no desgaste de válvulas submersas do sistema $\mathrm{ZrO}_{2}$ - grafite.

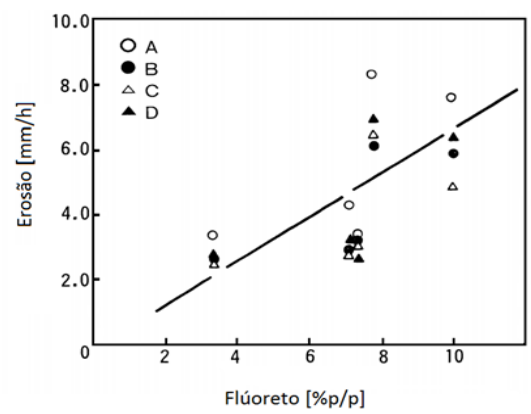

\begin{tabular}{|c|c|c|c|}
\hline \multirow{2}{*}{} & \multicolumn{3}{|c|}{$\begin{array}{c}\text { Composição química } \\
\text { dos refratários (\%) }\end{array}$} \\
\cline { 2 - 4 } & $\mathrm{C}$ & $\mathrm{SiC}$ & $\mathrm{ZrO}_{2}$ \\
\hline $\mathrm{A}$ & 22 & 11 & 63 \\
\hline $\mathrm{B}$ & 12 & 6 & 77 \\
\hline $\mathrm{C}$ & 13 & 8 & 76 \\
\hline D & 13 & 13 & 71 \\
\hline
\end{tabular}

Figura 1. Relação entre o teor de fluoreto e a erosão de refratários de $\mathrm{ZrO}_{2}$ - grafite [2].

Contudo, a substituição do flúor nos pós fluxantes não é direta e trivial. A presença do flúor na constituição dos pós fluxantes afeta sensivelmente a viscosidade da escória líquida e as características do filme formado na interface placa/molde. Ambos os aspectos são decisivos para o desempenho industrial do insumo. Assim, quando se busca a substituição ou redução dos teores de flúor nos pós fluxantes é necessária à utilização de outros compostos que confiram ao insumo as mesmas características indicadas ao uso.

Neste contexto, visando à busca de melhoria operacional foi proposto o desenvolvimento industrial de um pó fluxante com ultrabaixo teor de flúor (UBF) para o lingotamento contínuo de aços AA BC na Usiminas de Ipatinga. Assim, o presente trabalho visa apresentar os resultados industriais obtidos ao longo dos testes realizados em 2015 e 2016 na Aciaria 2 da Usiminas de Ipatinga.

\section{MATERIAIS E MÉTODOS}

Foram utilizados dois tipos de pós fluxantes sendo um deles com ultrabaixo teor de flúor (UBF), conforme características apresentadas na Tabela 1. 
Tabela 1. Características físico-químicas dos pós fluxantes

\begin{tabular}{|c|c|c|c|c|c|c|c|c|}
\hline \multirow{2}{*}{\multicolumn{2}{|c|}{ Pó fluxante }} & \multirow{2}{*}{$\mathrm{Ca} / \mathrm{SiO}_{2}$} & \multicolumn{4}{|c|}{ Teor de elementos (\%p/p) } & \multirow{2}{*}{$\begin{array}{l}\text { Viscosidade }^{(\bullet)} \\
\text { Poise a } 1300^{\circ} \mathrm{C}\end{array}$} & \multirow{2}{*}{$\begin{array}{c}\text { Cristalização }{ }^{(+)} \\
\left({ }^{\circ} \mathrm{C}\right)\end{array}$} \\
\hline & & & $\mathrm{Al}_{2} \mathrm{O}_{3}$ & $\mathrm{Na}_{2} \mathrm{O}$ & $\mathbf{F}$ & MnO & & \\
\hline \multirow{2}{*}{ UBF } & Mín. & 0,75 & 4,0 & 6,0 & - & 4,0 & \multirow{2}{*}{4,57} & \multirow{2}{*}{1132} \\
\hline & Máx. & 0,95 & 6,0 & 8,0 & 1,0 & 6,0 & & \\
\hline \multirow{2}{*}{ Ref. } & Mín. & 0,70 & 2,5 & 4,5 & 6,5 & - & \multirow{2}{*}{4,79} & \multirow{2}{*}{1083} \\
\hline & Máx. & 0,90 & 4,5 & 6,5 & 8,5 & - & & \\
\hline
\end{tabular}

(•) calculado conforme método de Rist.[3] (+) Calculado conforme método de Kim [4].

Os pós fluxantes apresentam, conforme especificação técnica, características bastante semelhantes em termos de viscosidade, temperatura de fusão e basicidade binária. Diferem-se principalmente pelos teores de sódio, manganês e flúor.

Os testes industriais foram realizados na Aciaria 2 da Usiminas de Ipatinga. Foram lingotadas, em máquina de lingotamento contínuo de placa de dois veios, 29 corridas de aços com baixo teor de carbono acalmado ao alumínio (AA BC). As corridas foram distribuídas em três séries de lingotamento com 12, 9 e 8 corridas cada uma. As características das séries são descritas na Tabela 2.

Tabela 2. Principais informações das corridas processadas em cada série

\begin{tabular}{lcccc}
\hline Séries & $\begin{array}{c}\text { Largura de } \\
\text { placa }\end{array}$ & $\begin{array}{c}\text { Espessura } \\
\text { de placa }\end{array}$ & Carbono visado & Manganês visado \\
\hline $1^{\mathrm{a}}$. & $1,23 \mathrm{~m}$ & $0,252 \mathrm{~m}$ & $0,04 \%$ & $0,23 \%$ \\
\hline $2^{\mathrm{a}}$. & $1,05 \mathrm{a} 1,23 \mathrm{~m}$ & $0,252 \mathrm{~m}$ & $0,04 \%$ & $0,23 \%$ \\
\hline $3^{\mathrm{a}}$. & $1,04 \mathrm{a} 1,23 \mathrm{~m}$ & $0,252 \mathrm{~m}$ & $0,04 \%$ & $0,21 \%$ \\
\hline
\end{tabular}

Na primeira série de corridas o pó fluxante UBF foi utilizado no veio par e o pó Referência no veio ímpar. Na segunda série foi realizada uma inversão de veios e mantida para a terceira série.

As corridas foram acompanhadas para avaliação global do desempenho do insumo no molde. Na primeira série acompanhada, foram coletadas amostras de escória no molde para identificar as variações de composição química durante o lingotamento. Foi também coletado filme de pó fluxante solidificado ao final da série com intuito de comparar as espessuras e as características morfológicas de cada um.

Dados do processo foram recolhidos e registrados. As temperaturas da placa do molde de cobre foram também analisadas para avaliação geral do comportamento do pó no veio.

Foram realizadas medidas de espessura da camada de escória líquida no molde e avaliado o consumo específico para entendimento das características de fusão e lubrificação do insumo. A medição da camada de escória líquida foi realizada próximo à válvula submersa, utilizando arame de aço recoberto com cobre de espessura de $0,8 \mathrm{~mm}$. O consumo específico foi estimado em função da quantidade de pó fluxante utilizado, em quilogramas, e do peso de aço lingotado, em toneladas.

As válvulas submersas utilizadas ao longo das séries foram recolhidas e analisadas com o intuito de avaliar as características gerais e o desgaste referente ao uso. $O$ desgaste foi estimado em função da relação entre a diferença do diâmetro externo inicial e diâmetro externo final da válvula submersa com o tempo de lingotamento.

Toda amostragem e medições ocorreram de forma simultânea em ambos os veios tanto para o pó fluxante UBF e para o pó fluxante Referência.

Os ensaios realizados nas amostras coletadas foram: i) análise química nas amostras de escória retiradas ao longo do processo e do filme final; ii) difração de raios $\mathrm{X}$ para identificação das fases cristalinas presentes no filme solidificado e no 
pó in natura; iii) análise térmica diferencial para determinação das temperaturas de cristalização dos filmes de pó fluxante recolhidos ao final de lingotamento.

\section{RESULTADOS E DISCUSSÃO}

Considerando as séries lingotadas foi processado um total de $1003 \mathrm{~m}$ de placas totalizando aproximadamente 2.373 toneladas de aço lingotados. Ao longo do processo não foram observadas anormalidades operacionais e/ou eventos que indicassem desvio de desempenho do pó fluxante UBF em relação ao pó Referência.

A fusão dos pós fluxantes é muito importante, na medida em que esse parâmetro permitirá avaliar a formação da camada de pó fluxante líquido na superfície livre do molde (menisco), o que garante a alimentação de pó fluxante na interface placa/molde ao longo dos ciclos de oscilação e, consequentemente, a lubrificação e o controle da transferência de calor no molde.

Por outro lado, quando a camada de pó fluxante líquida se forma em excesso podem ocorrer problemas, tais como, formação de uma borda sinterizada (slag rim) espessa nas paredes do molde, gerando interrupção ou dificuldades de alimentação do pó fluxante líquido.

A fusão é dependente das matérias-primas que constituem o fluxante, e suas respectivas temperaturas de fusão, tamanho e forma dos grãos, além do tipo e quantidade de carbono [5].

Do ponto de vista das características de fusão, considerando o efeito das propriedades dos pós fluxantes UBF e Referência na taxa de fusão, não foram realizados ensaios específicos. A taxa de fusão foi avaliada indiretamente pelos teores de carbono presentes em cada produto e pela relação entre o consumo específico e a camada de escória formada. Essas informações estão apresentadas na Tabela 3 e na Figura 2.

Tabela 3. Características dos pós fluxantes e consumo específico.

\begin{tabular}{c|c|c|c|c|c|c|c}
\hline \multirow{2}{*}{$\begin{array}{c}\text { Pó } \\
\text { fluxante }\end{array}$} & \multicolumn{2}{|c|}{ Carbono $(\%)$} & \multicolumn{2}{|c|}{ Temperatura $\left({ }^{\circ} \mathbf{C}\right)$} & \multicolumn{3}{c}{ Consumo específico (kg/t) } \\
\cline { 2 - 8 } & Livre & Total & Fusão & Fluidez & $\mathbf{1}^{\text {a }}$ série & $\mathbf{2}^{\mathbf{a}}$ série & $\mathbf{3}^{\mathbf{a}}$ série \\
\hline Ref. & 2,0 & 4,0 & 1064 & 1124 & 0,48 & 0,43 & - \\
\hline UBF & 5,5 & 6,5 & 1075 & 1108 & 0,45 & 0,40 & 0,41 \\
\hline
\end{tabular}

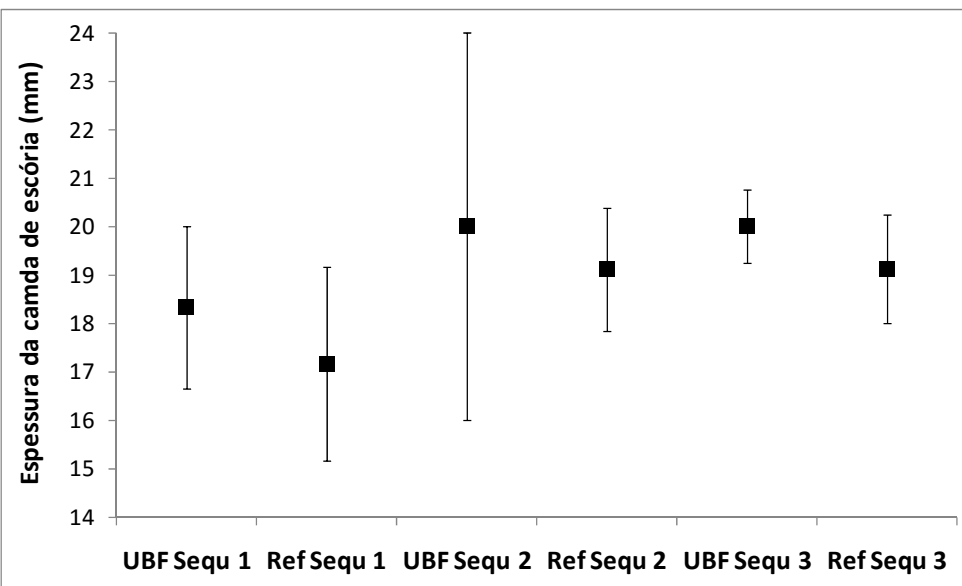

Figura 2. Comparativo das espessuras das camadas de escória líquida.

Conforme visto na Tabela 3, os pós fluxantes se diferem em relação aos teores de 
carbono e apresentam temperaturas de fusão semelhantes. Nos testes industriais, verificou-se que o consumo específico de ambos os pós fluxantes é semelhante. Outra questão importante é que não se verifica diferença estatística significativa, com $95 \%$ de confiança, nas médias das espessuras da camada de escória líquida medida em cada veio. Esta última afirmação somente é pertinente quando se compara os veios de uma mesma série de lingotamento. A comparação entre séries diferentes deixa de fazer sentido, tendo em vista que outros parâmetros podem influenciar na espessura das camadas medidas.

Considerado apenas aos teores de carbono, apresentados na Tabela 3 , a expectativa é que o pó fluxante Referência apresentasse uma taxa de fusão mais elevada. Entretanto, com base no consumo específico e na camada de escória líquida medidas não é possível fazer tal afirmação. Neste caso, o balanço entre consumo e formação da camada de escória líquida se manteve constante em ambos os casos, garantindo uma estabilidade operacional ao lingotamento contínuo. Assim, do ponto de vista das propriedades de fusão, entende-se que o pó fluxante UBF está de acordo com as necessidades operacionais para o lingotamento contínuo de aços AA BC na Usiminas.

A camada de pó fluxante líquida é responsável, também, pela absorção das inclusões não metálicas que flutuam no molde. Para aços AA BC a absorção de alumina é um fator significativo por afetar as características do pó fluxante.

A absorção de alumina pode ser representada pelo incremento deste composto na escória líquida, avaliada ao longo do sequencial de lingotamento. Na Figura 3 é apresentada a evolução do teor de alumina ao longo da primeira série de lingotamento para o pó fluxante UBF e Referência.

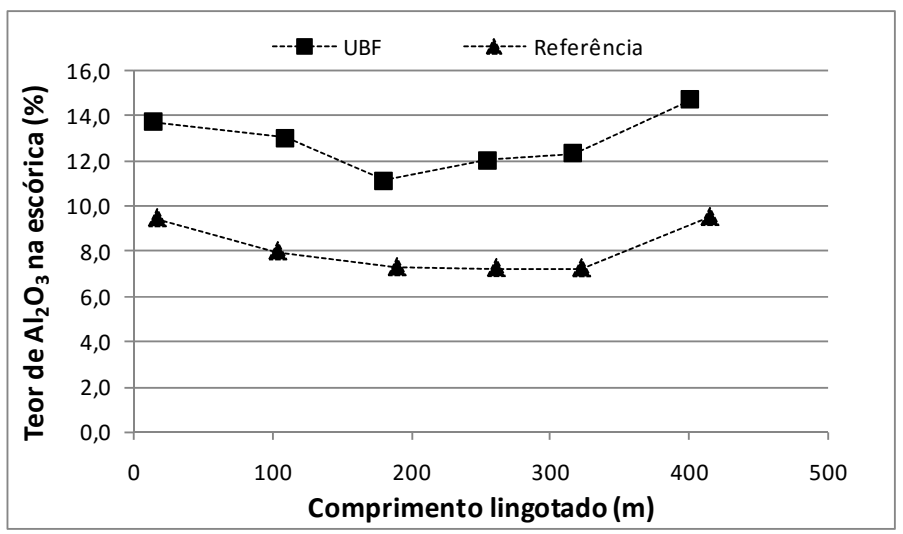

Figura 3. Evolução da alumina na escória líquida ao longo do lingotamento.

Conforme Figura 3, o pó fluxante UBF apresenta uma evolução de alumina superior ao longo de toda a série lingotada. Tendo em vista que os aços fabricados no sequencial são o mesmo para ambos os pós (máquina de dois veios) e o momento de amostragem é comum aos dois veios, não há de se falar em diferença de limpidez dos aços. O que pode ser apontado é a capacidade de absorção de inclusões ou, até mesmo, a maior interação da escória líquida com o alumínio do banho para o pó fluxante UBF. Do ponto de vista de capacidade de absorção de inclusões a bacicidade $\left(\mathrm{CaO} / \mathrm{SiO}_{2}\right)$ possui certo efeito e a presença de óxidos redutíveis como $\mathrm{SiO}_{2}$, $\mathrm{FeO}$ e $\mathrm{MnO}$ podem favorecer o incremento de alumina nas escórias [6].

Com base nas análises químicas realizadas nas amostras coletadas, é apresentado na Figura 4 a variação da basicidade e dos teores de $\mathrm{MnO}$ na escória líquida ao longo do processo de lingotamento. 

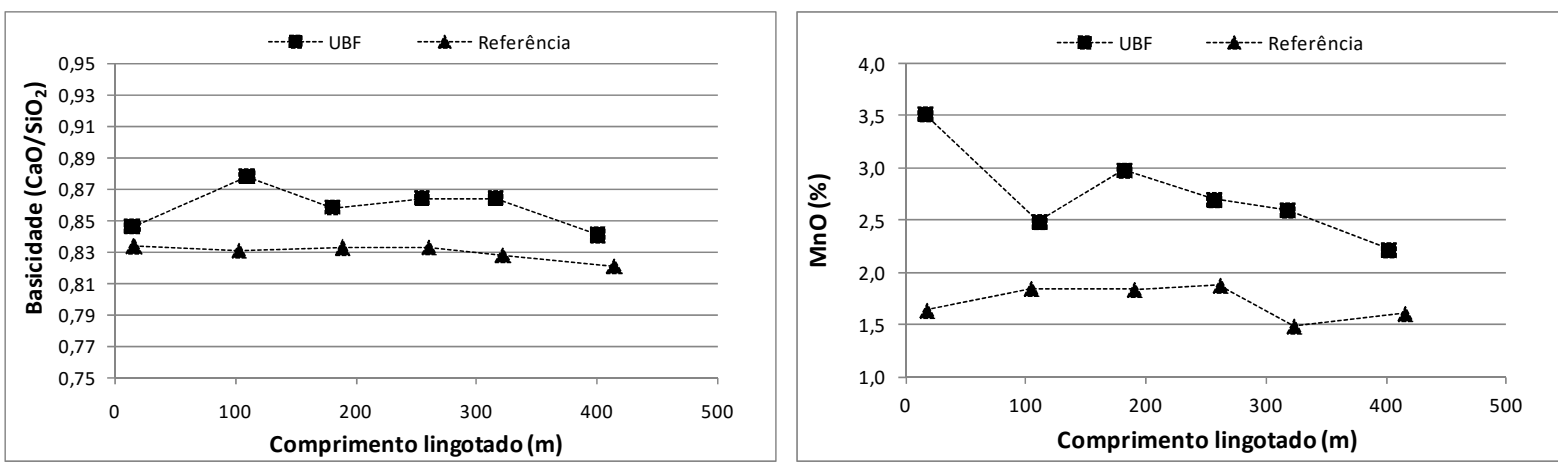

Figura 4. Evolução da basicidade e do teor de $\mathrm{MnO}$ na escória líquida ao longo do lingotamento.

A basicidade da escória líquida do pó fluxante UBF é sistematicamente mais elevada do que a do pó de Referência, além de existir uma tendência de redução do teor de $\mathrm{MnO}$. Tais fatos tendem a explicar a diferença no incremento de alumina observada. A importância principal das diferenças de alumina (diferenças médias em torno de $4 \%)$ está na alteração da viscosidade e das características de solidificação/cristalização do pó fluxante, podendo influenciar na lubrificação e nas características de extração de calor do molde [6].

Uma lubrificação adequada na região do molde garante a redução de defeitos superficiais e o risco de agarramento da pele em solidificação, que pode levar a acidentes operacionais ou redução de produtividade. A capacidade de lubrificação do fluxante líquido está diretamente ligada com sua viscosidade, mas também a parâmetros operacionais relativos ao processo (velocidade de lingotamento, condições de oscilação do molde, etc.).

Além da viscosidade, a temperatura de cristalização/solidificação do filme líquido infiltrado na interface placa/molde deve ser considerada para interpretação das características de lubrificação, ou seja, na interface placa/molde existe o filme sólido, em contato com a parede do molde, e filme líquido, em contato com a placa de aço em solidificação. De fato, ambas as camadas exercem capacidade de lubrificação, entretanto a lubrificação pelo filme líquido é preferida. Neste sentido, a temperatura de cristalização/solidificação afetará nas espessuras das camadas sólidas e líquidas presentes no filme.

Com relação à viscosidade, conforme especificação ambos os insumos apresentam semelhanças, quando avaliados in natura. Na Figura 5 são apresentados os resultados referentes aos ensaios de navículas inclinadas realizados utilizando ambos os pós fluxantes, comprovando a semelhança de viscosidade.
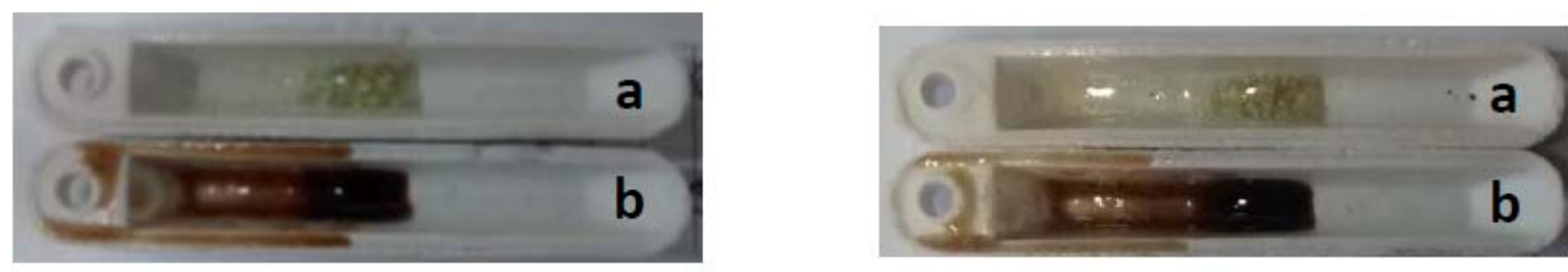

Figura 5. Ensaios de navículas inclinadas a $45^{\circ}$ realizados nos pós fluxantes em duplicata, a $1300^{\circ} \mathrm{C}$ : (a) Pó fluxante Referência e (b) pó fluxante UBF.

Entretanto, do ponto de vista de incorporação de alumina, conforme visto na Figura 3 é esperado que o insumo UBF, no veio, possua uma viscosidade superior, o que poderia afetar de forma relevante suas características gerais de operação. 
De qualquer forma, a viscosidade (ou capacidade de lubrificação) pode ser estimada indiretamente pelo consumo específico, que se reduz com o aumento da viscosidade.

Considerando que os pós fluxantes foram produzidos na mesma condição operacional e o fato do consumo ter se mostrado na mesma ordem de grandeza (variação de cerca de $7 \%$, pela metodologia de avaliação pode ser considerado baixa), é necessário investigar a propriedade física que balizou o efeito da incorporação de alumina e um incremento aparente de viscosidade, pode ser explicado pela variação nas temperaturas de solidificação para estes insumos.

Quando a temperatura de solidificação do fluxante é reduzida a espessura do filme líquido aumenta, favorecendo o escoamento, desde que não ocorra alteração na espessura do gap. Assim, o consumo de pó fluxante líquido na interface existente entre a placa/molde tende a aumentar com a redução da temperatura de solidificação.

Neste sentido, foi realizada uma avaliação das condições de solidificação dos pós fluxantes a fim de avaliar suas temperaturas de solidificação. Para tanto, utilizou-se os resultados da análise térmica diferencial (ATD). O ensaio foi realizado em cadinho de platina com $150 \mathrm{mg}$ de filme de pó fluxante moído, aquecido a $1300^{\circ} \mathrm{C}$ com uma taxa de $10^{\circ} \mathrm{C} / \mathrm{min}$ e resfriado na mesma taxa em ambiente inerte.

Os resultados obtidos via análise térmica diferencial no resfriamento dos filmes de escória obtidos no final de série mostram que existe uma diferença nas temperaturas de solidificação destes insumos. Para o pó fluxante UBF observa-se o início do pico característico de solidificação a $1075^{\circ} \mathrm{C}$ e para o pó fluxante Referência este pico inicia-se a $1150^{\circ} \mathrm{C}$, aproximadamente. Finaliza-se a 950 e $1050^{\circ} \mathrm{C}$, respectivamente. A alteração na temperatura de solidificação está possivelmente associada, também, às diferenças de incorporação de alumina [6].

Associado à redução das temperaturas de solidificação percebe-se uma ligeira redução da espessura do filme solidificado, conforme apresentado na Figura 6.
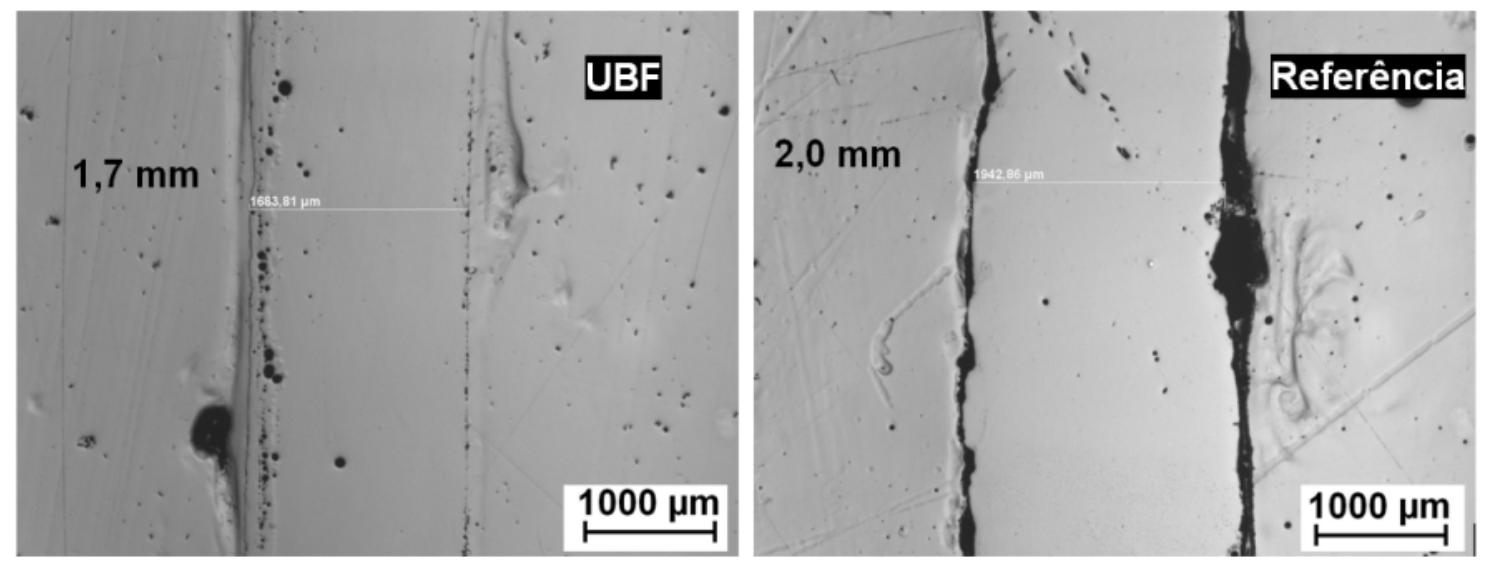

Figura 6. Micrografia de aspecto dos filmes de pó fluxante obtidos no final do lingotamento.

Outro parâmetro que colabora com o efeito do incremento da alumina é a cristalinidade do filme. Tal característica foi avaliada via difração de raios $X$ realizada no filme coletado ao final de lingotamento. A Figura 7 apresenta os espectros de difração de raios $X$ para os filmes de pó fluxantes estudados. 

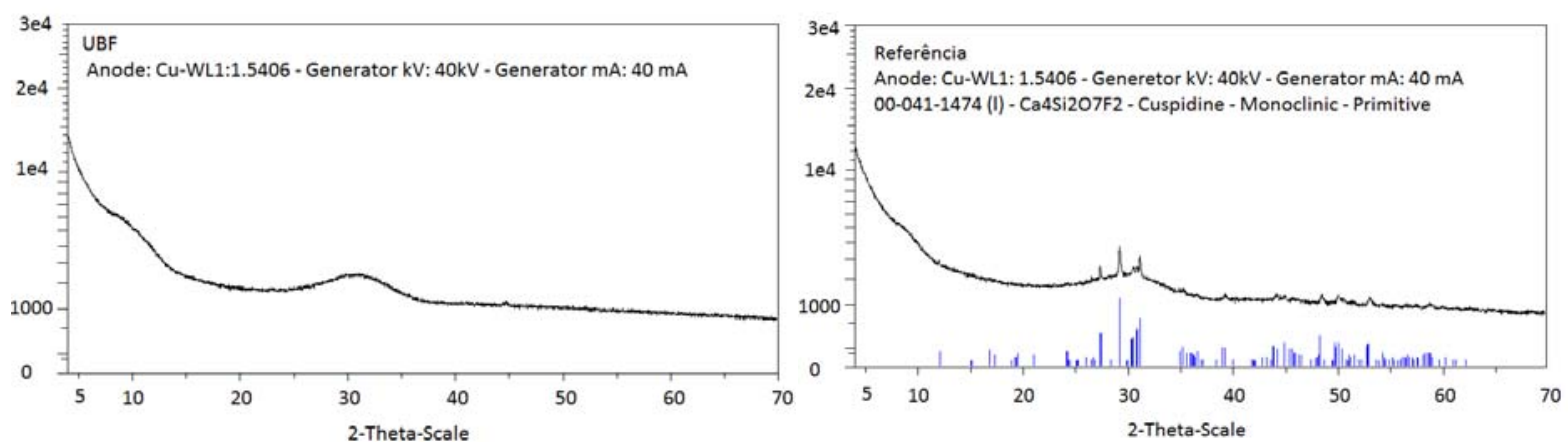

Figura 7. Espectro de difração de raios $\mathrm{X}$ para os filmes de pó fluxante obtidos no final de lingotamento.

Conforme Figura 7, o aspecto amorfo é presente em ambos os filmes solidificados. Entretanto, o filme formado a partir do pó fluxante Referência apresenta uma pequena fração de fase cristalina, e esta fase é constituída de cuspidina.

Todo o aspecto de consumo, cristalização, viscosidade etc., irão influenciar de maneira ou de outra no comportamento térmico do molde. O comportamento térmico do molde pode ser visualizado por meio das temperaturas da placa de cobre e do fluxo de calor global avaliado em função das vazões e da variação da temperatura da água do resfriamento do molde.

Na Figura 8 são apresentadas as médias das temperaturas do molde de cobre em função do comprimento lingotado para cada veio.
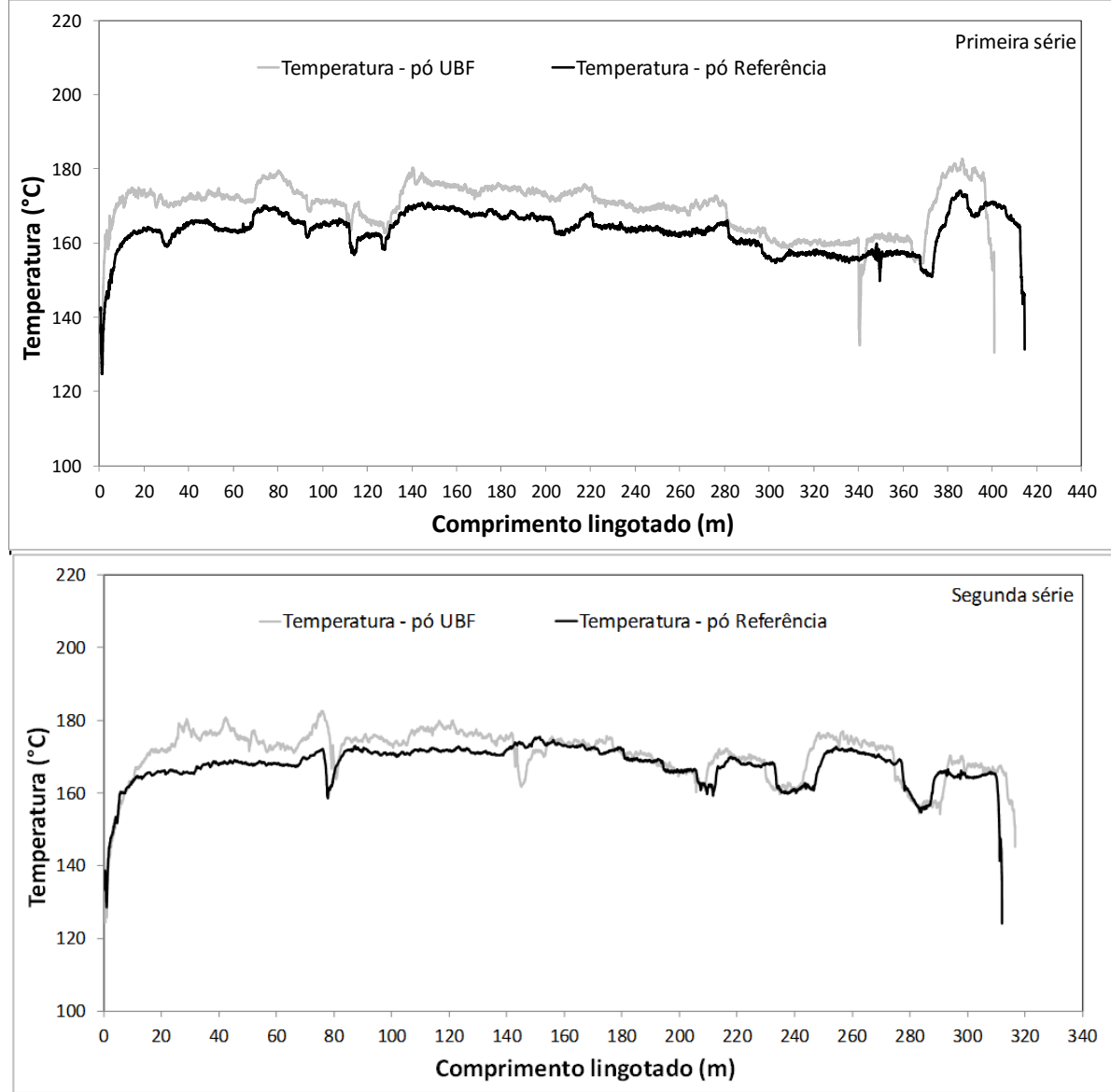

Figura 8. Média das temperaturas da placa de cobre do molde.

Com relação ao comportamento térmico no molde, verifica-se uma temperatura da placa de cobre superior quando se utiliza o pó fluxante UBF. De fato, esta elevação 
da temperatura está de acordo com as características do filme do pó fluxante caracterizado. Uma vez que a espessura do filme do pó fluxante formado com o pó UBF é menor e ele apresenta-se mais vítreo, há uma menor resistência ao fluxo térmico favorecendo a extração de calor no molde.

As análises de recusa em produto acabado das três séries de lingotamento foram feitas para os veios onde usou o pó UBF e para o pó Referência. Não foi observado desvio ou recusa para ambos os veios, quando considerados defeitos do tipo inclusão de pó e esfoliamento. Assim, com relação à qualidade superficial de produto laminado o pó fluxante UBF atende as necessidades atuais da Usiminas.

Por fim, a comparação do desgaste de válvula submersa foi avaliada nas duas primeiras séries lingotadas. A Figura 9 apresenta a fotografia de aspecto das válvulas submersas utilizadas na primeira série de lingotamento acompanhada. Nesta série de lingotamento foram utilizadas duas válvulas submersas em cada veio. Na primeira válvula utilizada foram realizadas duas linhas de desgaste.

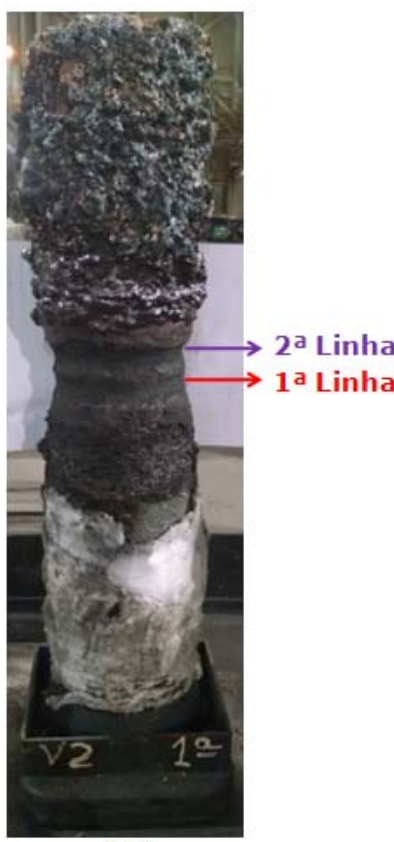

(a)
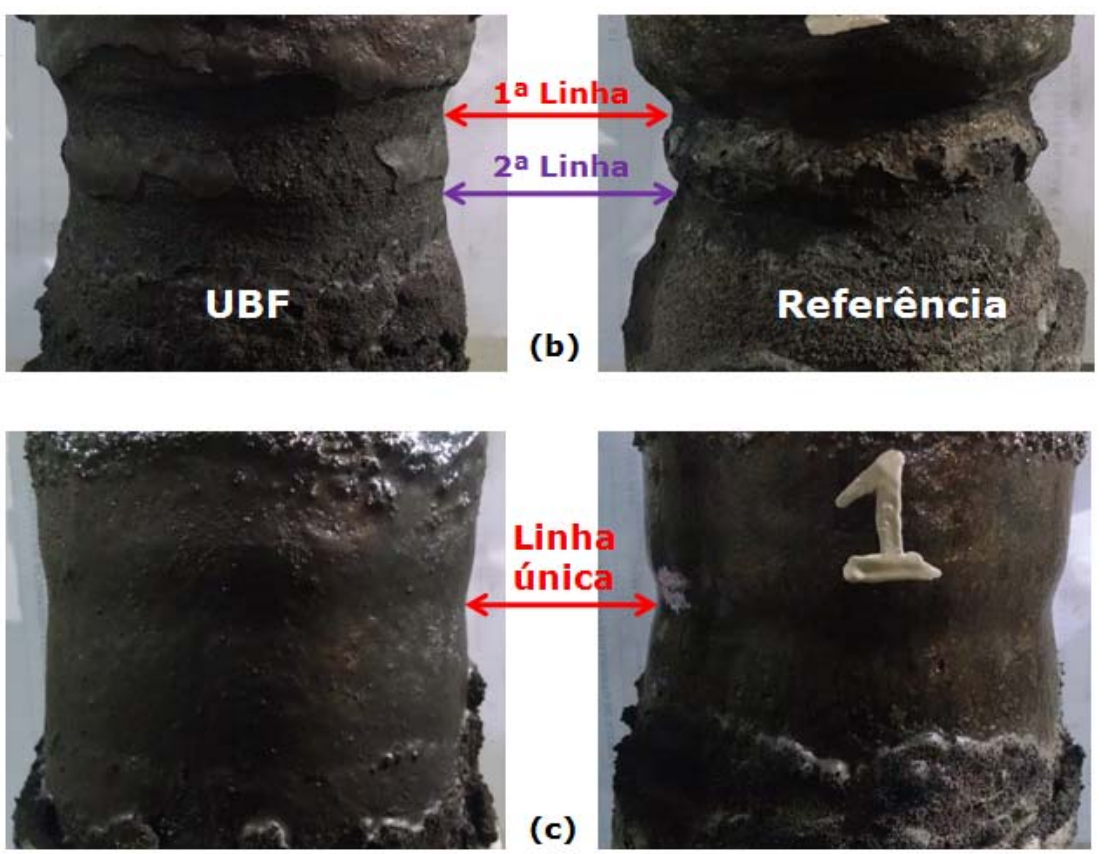

Figura 9. Aspecto geral da válvula submersa (a) válvula submersa utilizada por aproximadamente 6,0 horas (b) e válvula submersa utilizada por aproximadamente 1,5 horas (c).

Na Figura 9 é visualmente perceptível o menor desgaste associado à válvula do veio no qual se utilizou o pó fluxante UBF. O remanescente de parede e o desgaste medido para cada situação são apresentados na Tabela 4.

Tabela 4. Aspectos referentes ao uso e desgaste das válvulas submersas.

\begin{tabular}{c|c|c|c|c|c|c}
\hline \multirow{2}{*}{ Séries } & \multirow{2}{*}{$\begin{array}{c}\text { Posição da } \\
\text { válvula na } \\
\text { série }\end{array}$} & \multirow{2}{*}{$\begin{array}{c}\text { Pó } \\
\text { fluxante }\end{array}$} & \multicolumn{2}{c|}{$\begin{array}{c}\text { Remanescente de } \\
\text { parede }(\mathbf{m m})\end{array}$} & \multicolumn{2}{c}{$\begin{array}{c}\text { Desgaste } \\
\text { (mm/min) }\end{array}$} \\
\cline { 3 - 7 } & \multirow{2}{*}{ Primeira } & UBF & 19,347 & 19,029 & 0,047 & 0,047 \\
\cline { 3 - 7 } & & Ref. & 15,048 & 15,366 & 0,072 & 0,066 \\
\hline \multirow{3}{*}{ Primeira } & \multirow{2}{*}{ Segunda } & UBF & 24,603 & - & 0,043 & - \\
\cline { 3 - 7 } & & Ref. & 23,009 & - & 0,062 & - \\
\hline \multirow{2}{*}{ Segunda } & \multirow{2}{*}{ Primeira } & UBF & 19,347 & 23,009 & 0,044 & 0,035 \\
\cline { 3 - 7 } & & Ref. & 13,456 & 19,029 & 0,076 & 0,071 \\
\hline
\end{tabular}


Os resultados de desgaste da válvula submersa mostram um ganho relevante com o uso do pó fluxante UBF. A taxa média de desgaste foi aproximadamente $40 \%$ inferior à obtida com o uso do pó fluxante comercial de Referência. Tal observação é relevante tanto do ponto de vista da segurança quanto do custo operacional.

\section{CONCLUSÃO}

O desempenho industrial do pó fluxante denominado ultrabaixo teor de flúor UBF, com teor máximo de $1,0 \%$ de flúor, foi considerado satisfatório, quando comparado ao pó Referência que contém $7,5 \%$ de flúor, quando utilizado em aços com baixo teor de carbono acalmado ao Alumínio (AA BC). Tanto as caracterizações realizadas quanto o desempenho industrial evidenciam que as propriedades relativas à taxa de fusão, lubrificação e cristalização estão de acordo com as necessidades operacionais para a produção de aços AA BC na Aciaria 2 da Usiminas em Ipatinga.

Os produtos laminados não apresentaram recusa ou desvio por defeitos do tipo inclusão de pó ou esfoliamento. Indicando que não houve alteração na qualidade superficial da placa produzida com o uso do pó fluxante UBF.

Os resultados de desgaste da válvula submersa mostram um ganho significativo com o uso do pó fluxante UBF. A taxa média de desgaste foi aproximadamente $40 \%$ inferior à obtida com o uso do pó fluxante comercial.

\section{REFERÊNCIAS}

1 FONSECA, M. V. de A.; GULUZZIO, L. M. L. A vaporização de flúor a partir de fluxantes utilizados no LC de aços: a influência da formulação e as consequências da perda de lubrificação na interface placa/molde. In: $\mathbf{5 6}^{\circ}$ Congresso Anual da Associação Brasileira de Metalurgia e de Materiais. Brasil: Associação Brasileira de Metalurgia e Materiais - ABM, Belo Horizonte, MG, 2001.

2 NAKAMURA, Y.; ANDO, T.; KURATA, K.; IKEDA, M. Effect of Chemical Composition of Mold Powder on the of Submerged Nozzles for Continuous Casting of Steel. Transactions ISIJ. Vol. 26, 1986, pp 1052 - 1058.

$3 \mathrm{KIM}, \mathrm{J}$. W. et al. Viscous characteristics of synthetic mold powder for high speed continuous casting. In: Proc. International Conference on Molten Slags and Fluxes. 4, p. 468, 8-11 jun. 1992.

4 STURGILL, D. Mold fluxes for continuous casting: theory and workshop. Urbana: CV Materials, Ltd., 1999. 1V.

5 MOORE, J. A.; PHILLIPS R. J.; GIBBS T. R. In: overview for the requiremens of continuous casting mold fluxes. Steelmaking Conference Proceedings. Vol. 74: Washington, DC, 1991. pp 615-621.

6 MILLS, K. Mould powders for continuous casting. Centre for Materials Measurement and Technology. Department of Materials. Imperial College. London. Trabalho não publicado. 